\title{
AIRBORNE LASER BATHYMETRY FOR DOCUMENTATION OF SUBMERGED ARCHAEOLOGICAL SITES IN SHALLOW WATER
}

\author{
M. Doneus ${ }^{1,2, *}$ I. Miholjek ${ }^{3}$, G. Mandlburger ${ }^{4}$, N. Doneus², G. Verhoeven ${ }^{2}$, Ch. Briese ${ }^{4,5}$, M. Pregesbauer ${ }^{2}$ \\ ${ }^{1}$ Department of Prehistoric and Historical Archaeology, University of Vienna, Franz-Kleingasse 1, 1190 Wien, Austria, \\ ${ }^{2}$ LBI for Archaeological Prospection \& Virtual Archaeology, Hohe Warte 38, 1190 Wien, Austria, \\ ${ }^{3}$ Department for Underwater Archaeology, Croatian Conservation Institute, Nike Grškovića 23, 10000 Zagreb, Croatia, \\ ${ }^{4}$ Department of Geodesy and Geoinformation, Vienna University of Technology, Gusshausstrasse 27-29, 1040 Wien, Austria, \\ ${ }^{5}$ Earth Observation Data Centre (EODC), Gusshausstrasse 27-29, 1040 Wien, Austria.
}

\section{Commission V}

KEY WORDS: airborne laser scanning, airborne laser bathymetry, green laser, archaeological prospection, underwater, submerged site, Roman harbour, lake dwelling

\begin{abstract}
:
Knowledge of underwater topography is essential to the understanding of the organisation and distribution of archaeological sites along and in water bodies. Special attention has to be paid to intertidal and inshore zones where, due to sea-level rise, coastlines have changed and many former coastal sites are now submerged in shallow water. Mapping the detailed inshore topography is therefore important to reconstruct former coastlines, identify sunken archaeological structures and locate potential former harbour sites. However, until recently archaeology has lacked suitable methods to provide the required topographical data of shallow underwater bodies. Our research shows that airborne topo-bathymetric laser scanner systems are able to measure surfaces above and below the water table over large areas in high detail using very short and narrow green laser pulses, even revealing sunken archaeological structures in shallow water. Using an airborne laser scanner operating at a wavelength in the green visible spectrum $(532 \mathrm{~nm})$ two case study areas in different environmental settings (Kolone, Croatia, with clear sea water; Lake Keutschach, Austria, with turbid water) were scanned. In both cases, a digital model of the underwater topography with a planimetric resolution of a few decimeters was measured. While in the clear waters of Kolone penetration depth was up to 11 meters, turbid Lake Keutschach allowed only to document the upper 1.6 meters of its underwater topography. Our results demonstrate the potential of this technique to map submerged archaeological structures over large areas in high detail providing the possibility for systematic, large scale archaeological investigation of this environment.
\end{abstract}

\section{INTRODUCTION}

In archaeological topographic research there is a gap between land surfaces including tidal zones and underwater environments. This is a result of two factors, where (1) different archaeological methods are being used for these differing physical environments, and (2) extremely shallow underwater bodies between 0 and $5 \mathrm{~m}$ depth can hardly be documented with existing methods. This is unfortunate since knowledge of this shallow offshore underwater topography is essential to the understanding of the organisation and distribution of archaeological sites along and in water bodies. Special attention has to be paid to intertidal and inshore zones where, due to sea-level rise, coastlines have changed and many former coastal sites are now submerged in shallow water (Lambeck et al., 2004). Mapping the detailed inshore topography is therefore important to reconstruct former coastlines, identify sunken archaeological structures and locate potential former harbour sites. Bridging the "border" between land and water in archaeological topographic research therefore requires the development of new archaeological documentation methods.

Until now archaeology has been lacking suitable methods to provide the required topographical data of shallow underwater bodies between 0 and $5 \mathrm{~m}$ water depth (see also: Doneus et al., 2013). Due to practical constraints and depending on the pulse length, waterborne echo sounding has its limitations at shallow water depths (Jong, 2002, 322). Tachymetric surveys, i.e. the use of total station and GPS are extremely timeconsuming, small-scale, and do not feature the necessary details. Airborne photogrammetry has been applied and although it proves to be a relatively low-cost method that can be used for mapping large areas, its success is strongly depending on many specific weaknesses such as illumination variations and refraction behaviour (see Carbonneau et al., 2006 for a more in-depth discussion). Finally, airborne laser scanning (ALS) systems operating in the NIR region of the electromagnetic spectrum (usually @ 1064 and 1550 nm wavelength) do not penetrate the water column. Up to recently, those systems operating with green laser (@532 nm - so called hydrographic or bathymetric ALS systems Guenther et al., 2000) are designed for maximum water penetration and the moderate pulse repetition rate results in a rather coarse ground sampling distance of several meters (e.g. Cunningham et al., 1998; McNair, 2010, 24ff.). Therefore, they are not suitable for detection and documentation of archaeological sites and structures.

Only the latest generation of airborne laser bathymetry (ALB) scanner systems which are now becoming available, utilise 
very short and narrow green laser pulses resulting in underwater surfaces over large areas in high detail (ground sampling distance $<50 \mathrm{~cm}$ ). This paper builds upon a previous publication (Doneus et al., 2013) and focuses on the concept of ALB and currently available systems. Finally, two case studies - a Roman harbour location in the extremely clear waters of the Northern Adriatic and a lake dwelling located in a turbid Austrian lake - are contrasted and potential and limitations discussed.

\section{AIRBORNE LASER BATHYMETRY}

In the year 2000, ALS systems were introduced to archaeology (Doneus and Briese, 2011, 61). Today, it has become a viable method of data acquisition for detailed digital terrain models (DTM) in open fields, meadows or forested and otherwise densely vegetated areas. They usually operate in the near- or short-wavelength infrared (typically $1064 \mathrm{~nm}$ or $1550 \mathrm{~nm}$, respectively), which is significantly absorbed by water bodies.

ALB necessitates a laser which allows water penetration to document underwater topography. Since the effectively usable spectral region for water penetration is generally limited to the blue and green EM spectral region between about 400-600 nm (Pope and Fry, 1997; Bukata et al., 1995), a green pulse at 532 $\mathrm{nm}$ is used in most ALB systems (Table 1).

While the basic operating principle is the same as with ALS scanners, the processing of the signals is complicated by the signal propagation in different optical media (air and waterFigure 1). This comprises a deflection of the green laser beam at the air-water-interface and a reduced laser propagation speed in the water. The refraction angle depends on the incidence of the laser beam with the water surface and is described by Snell's law of refraction. To keep the incidence angle constant (maximum deviation of $\pm 1^{\circ}$ over the entire scan range of $40^{\circ}$ assuming a perfectly horizontal water surface), the laser pulses are usually tilted by $20^{\circ}$ from the nadir direction resulting in circular or elliptic scan lines (Mandlburger et al., 2011, 2418; for a detailed discussion of the nadir angle see Guenther et al., 2000, 10ff.). Within the water body, the laser beam is further spread due to the optical properties of water. As a consequence, the illuminated portion of the bottom increases as does the uncertainty in depth estimation (for a more detailed discussion, see Doneus et al., 2013, 2139f.).

The penetration capability of an ALB system is a function of instrument specific parameters and of environmental conditions. The main variables affecting penetration depth are energy and length of the individual laser pulse, beam divergence with flying height and resulting footprint size, clarity of the atmosphere, water surface roughness, water clarity, and seafloor reflectivity. Highest penetration rates can be achieved using long and high energy pulses at calm days over clear water and well reflecting sea floors. However, due to the involved environmental variables, which will be different for each data acquisition campaign and even may change during an ALB scan, it is not possible to specify penetration depth in absolute values. Therefore, a relative measure is used to define the maximum achievable water penetration depth. It is the so called Secchi depth, which is actually a measure for turbidity of water and denotes the maximum depth at which a black and white or all white disk with $30 \mathrm{~cm}$ diameter disappears from view by the unaided human eye (Preisendorfer, 1986).

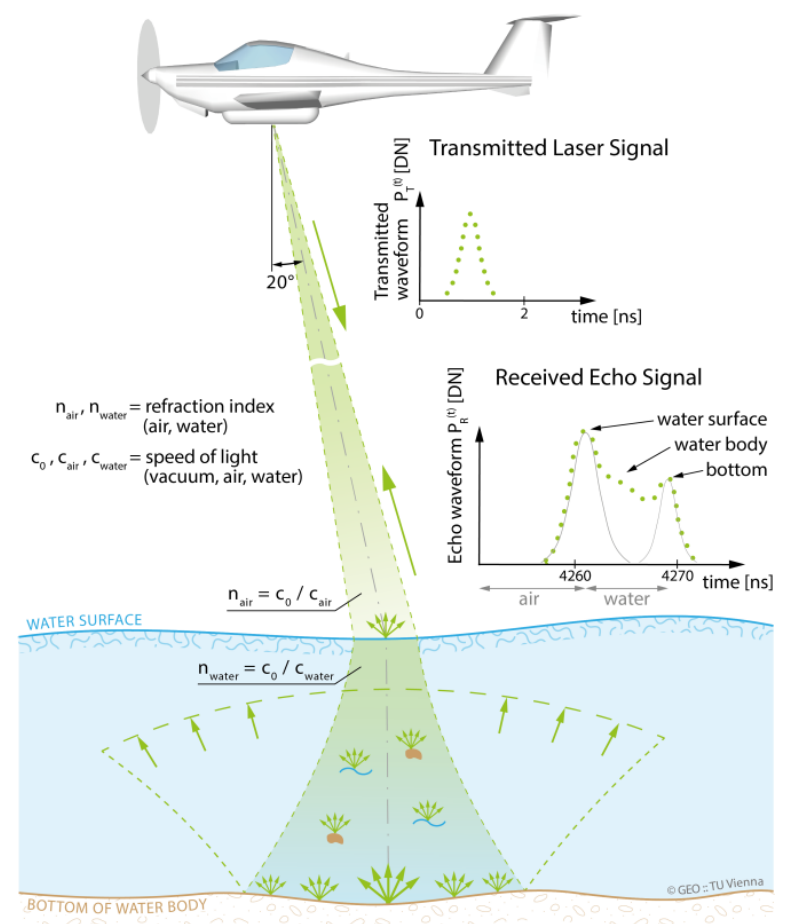

Figure 1. Diagram explaining ALB. See text for further information (CDepartment of Geodesy and Geoinformation Research Group Photogrammetry, E120.7).

\subsection{ALB Systems}

Up to recently, ALB systems were mainly designed for maximum penetration of water bodies using long $(\sim 7 \mathrm{~ns})$ and high radiant energy $(\sim 5 \mathrm{~mJ})$ laser pulses with a typical pulse repetition rate of approximately $1 \mathrm{kHz}$. For eye safety reasons, these instruments spread the green laser beam to a diameter of several meters. As a result, these devices can penetrate a water body of up to 3 Secchi depths yielding ground sampling distances of $4-5 \mathrm{~m}$ at typical flying heights between $200 \mathrm{~m}$ and $500 \mathrm{~m}$ (Guenther et al., 2000, 3-5). While this allows for the generation of sophisticated underwater topography models, which can be used in archaeological research (Prahov et al., 2011; Tian-Yuan Shih et al., 2014), the resolution is too low for the archaeological documentation of submerged sites and individual features.

Meanwhile (at the time of writing, i.e. February 2015) a few systems have become available that have a higher scan rate and a relatively small footprint (Table 1). They seem to be very promising for archaeological research purposes. However, to guarantee eye safety, the smaller footprint requires the radiant energy to be lowered. This results in a 


\begin{tabular}{|c|c|c|c|c|c|c|c|c|c|}
\hline Sensor & IR & Green & Camera & $\begin{array}{c}\text { Scanrate } \\
\text { Topo } \\
\text { [kHz] }\end{array}$ & $\begin{array}{c}\text { Scanrate } \\
\text { Bathy } \\
\text { [kHz] }\end{array}$ & $\begin{array}{l}\text { Depth } \\
\text { range } \\
\text { [Secchi] }\end{array}$ & $\begin{array}{l}\text { Foot- } \\
\text { print ") } \\
{[\mathrm{cm}]}\end{array}$ & $\begin{array}{c}\text { Scan } \\
\text { pattern }\end{array}$ & $\begin{array}{l}\text { Weight } \\
\text { [kg] }\end{array}$ \\
\hline $\begin{array}{l}\text { Optech } \\
\text { Aquarius }\end{array}$ & & 1 & $\begin{array}{l}\text { Video } \\
\text { (RGB) }\end{array}$ & 70 & 70 & 1.0 & 50 & $\begin{array}{l}\text { Circle } \\
\left(20^{\circ}\right)\end{array}$ & 83 \\
\hline $\begin{array}{l}\text { Optech } \\
\text { CZMIL }\end{array}$ & & 1 & $\begin{array}{c}\text { RGB+ } \\
\text { Hypersp. } \\
\text { +Thermal }\end{array}$ & 70 & 10 & 3.0 & 350 & $\begin{array}{l}\text { Circle } \\
\left(20^{\circ}\right)\end{array}$ & $>300$ \\
\hline $\begin{array}{l}\text { Optech } \\
\text { Titan }\end{array}$ & 2 & 1 & $R G B+I R$ & $15-300$ & $15-300$ & 1.0 & 35 & Line & 71 \\
\hline $\begin{array}{c}\text { Leica } \\
\text { Chiroptera II }\end{array}$ & 1 & 1 & $R G B+I R$ & 500 & 35 & 1,5 & 150 & $\begin{array}{l}\text { Ellipse } \\
\left(14 / 20^{\circ}\right)\end{array}$ & 80 \\
\hline $\begin{array}{c}\text { Leica } \\
\text { HawkEye III }\end{array}$ & 1 & 2 & $R G B+I R$ & 500 & $35 / 10$ & $1.5 / 3.0$ & $\begin{array}{c}150 / \\
\text { ca. } 350\end{array}$ & $\begin{array}{l}\text { Ellipse } \\
\left(14 / 20^{\circ}\right)\end{array}$ & 170 \\
\hline $\begin{array}{l}\text { Riegl LMS } \\
\text { VQ-820-G }\end{array}$ & - & 1 & - & 200 & 200 & 1.0 & 50 & $\begin{array}{l}\text { Elliptical } \\
\operatorname{arc}\left(20^{\circ}\right)\end{array}$ & 25 \\
\hline $\begin{array}{l}\text { Riegl LMS } \\
\text { VQ-880-G }\end{array}$ & (1) & 1 & $\begin{array}{l}\text { RGB } \\
\text { (NIR) }\end{array}$ & 550 & 550 & 1.5 & $35-100$ & $\begin{array}{l}\text { Circle } \\
\left(20^{\circ}\right)\end{array}$ & 60 \\
\hline
\end{tabular}

*) Laser footprint on the ground assuming a flying height of $500 \mathrm{~m}$ a.g.I

Table 1. Compilation of recent ALB scanning systems (ㄷ Gottfried Mandlburger).

reduced water penetration capability typically between 1 and 1.5 Secchi depths. Of special interest are Leica HawkEye-III (AHAB 2014), Optech Titan (Optech 2014) and RIEGL LMS VQ-880-G (RIEGL 2014). While Leica's HawkEye III is extremely performant with two green laser sources for shallow and deep water, Optech's Titan is operating simultaneously with two infrared (1064 $\mathrm{nm}$ and $1550 \mathrm{~nm})$ and one green $(532 \mathrm{~nm})$ laser source providing not only the possibility to survey submerged surfaces but also a spectral analysis of scanned objects (see also Briese et al., 2014). RIEGL's VQ-880-G has a high scan rate and slightly better penetration capability, which allows acquiring more detail of underwater surfaces.

For our case studies, which had been measured already in 2012 (see below), the hydrographic laser scanner VQ-820-G had been used, which was manufactured by the company RIEGL Laser Measurement Systems GmbH in cooperation with the University of Innsbruck, Unit of Hydraulic Engineering, was used (RIEGL 2012). It was designed to yield ground sampling distances less than $1 \mathrm{~m}$. This is achieved using very short laser pulses (1 ns allowing good range discrimination and narrow laser beams) with small footprints (in our case $0.45 \mathrm{~m}$ at a flying height of $450 \mathrm{~m}$ ) and a high effective measurement rate $(200 \mathrm{kHz})$ while providing a depth penetration performance of up to one Secchi depth.

\section{CASE STUDIES}

To demonstrate the archaeological potential and limitation of ALB, two case study areas with different water quality were chosen (Figure 2). Both case study areas are different in terms of environmental conditions.

(1) The coastal area of the bay of Kolone (Croatia), containing a Roman harbour site with fish ponds in the southwest of Croatian Istria. It has been known for stone artefacts and underwater structures dating to the Roman period. The islet
Kolona, located in the Kolone bay, was a peninsula during the Roman period. Today, the connection to the mainland is submerged due to sea level rise. The research on the site has started in 2009 by the Croatian Conservation Institute (HRZ) which has conducted several underwater surveys till 2012. The water can be very clear on calm days, as displayed in the orthophoto mosaic that was photographed simultaneously with the ALB data acquisition in March 2012 (Figure 3).

(2) The area of Lake Keutschach in the southern part of Austria which contains a late Neolithic lake dwelling (Samonig 2003; Cichocki and Dworsky 2006). The waters of the alpine Lake Keutschach - although of high quality contain suspended sediments and are therefore less clear. The orthophoto mosaic - again acquired during the ALB flight shows the underwater surface only in extremely shallow areas along the lakeshore and at the oval shaped shallowness, where the late Neolithic lake dwelling is located (see arrow in Figure 4).

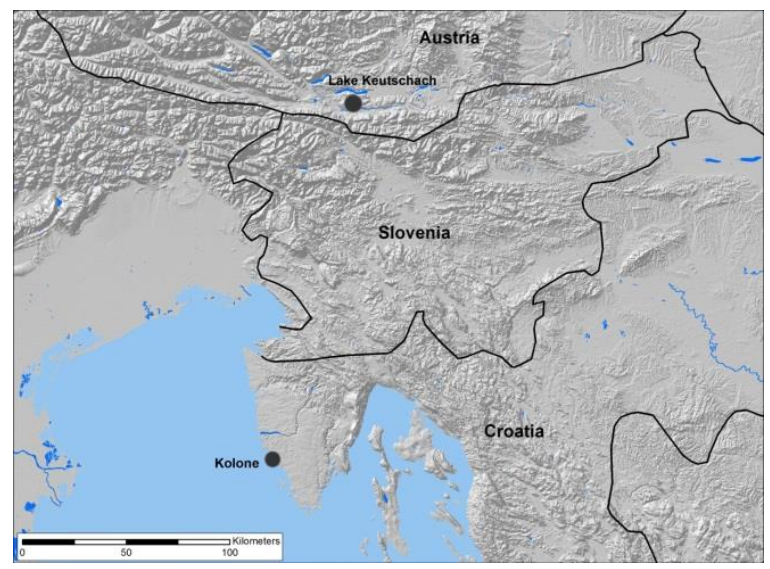

Figure 2. Geographical location of the two case study areas. 


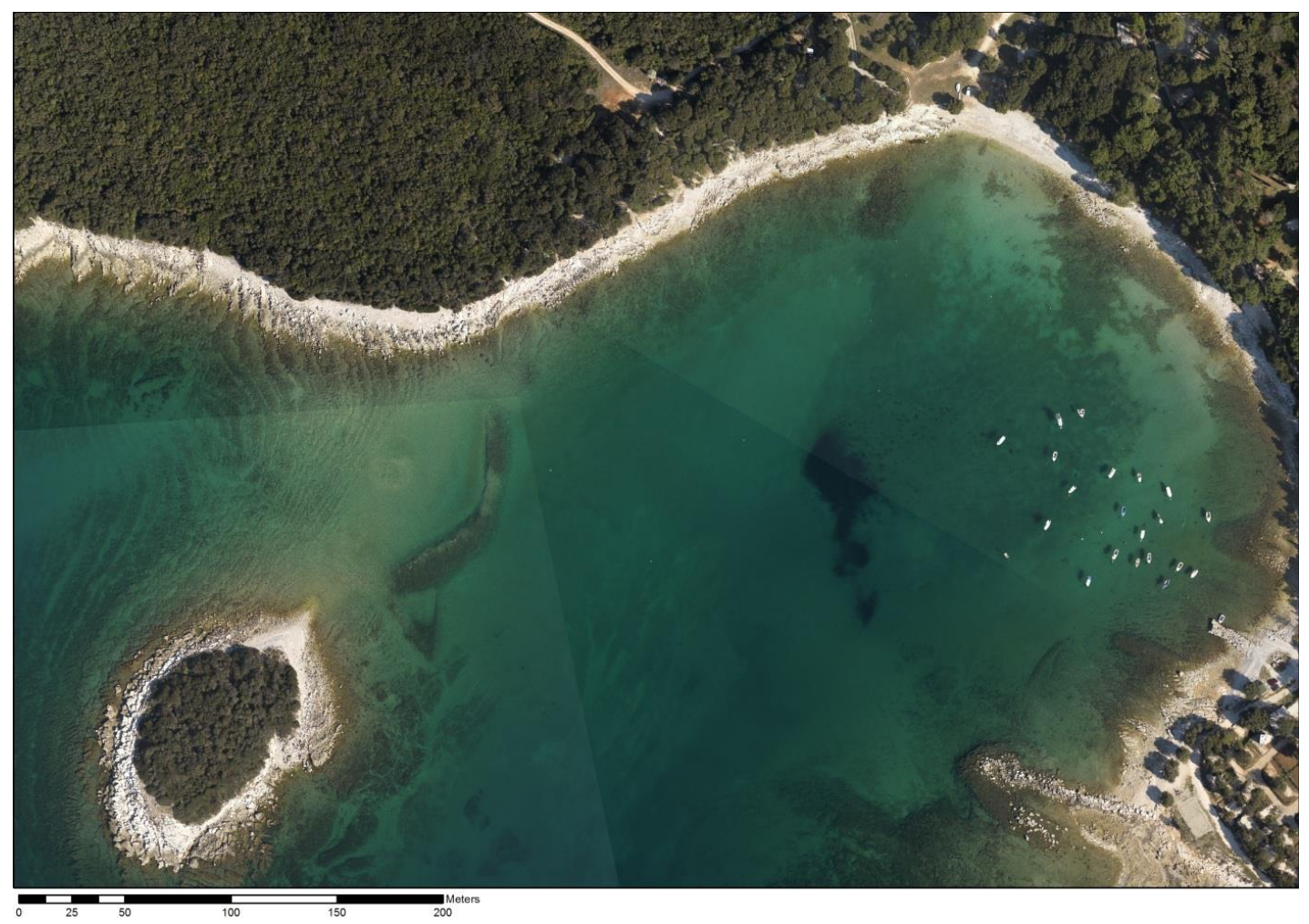

Figure 3. Case study area Kolone. Simultaneously acquired orthophoto mosaic showing the situation of the ancient harbour area. North is up.

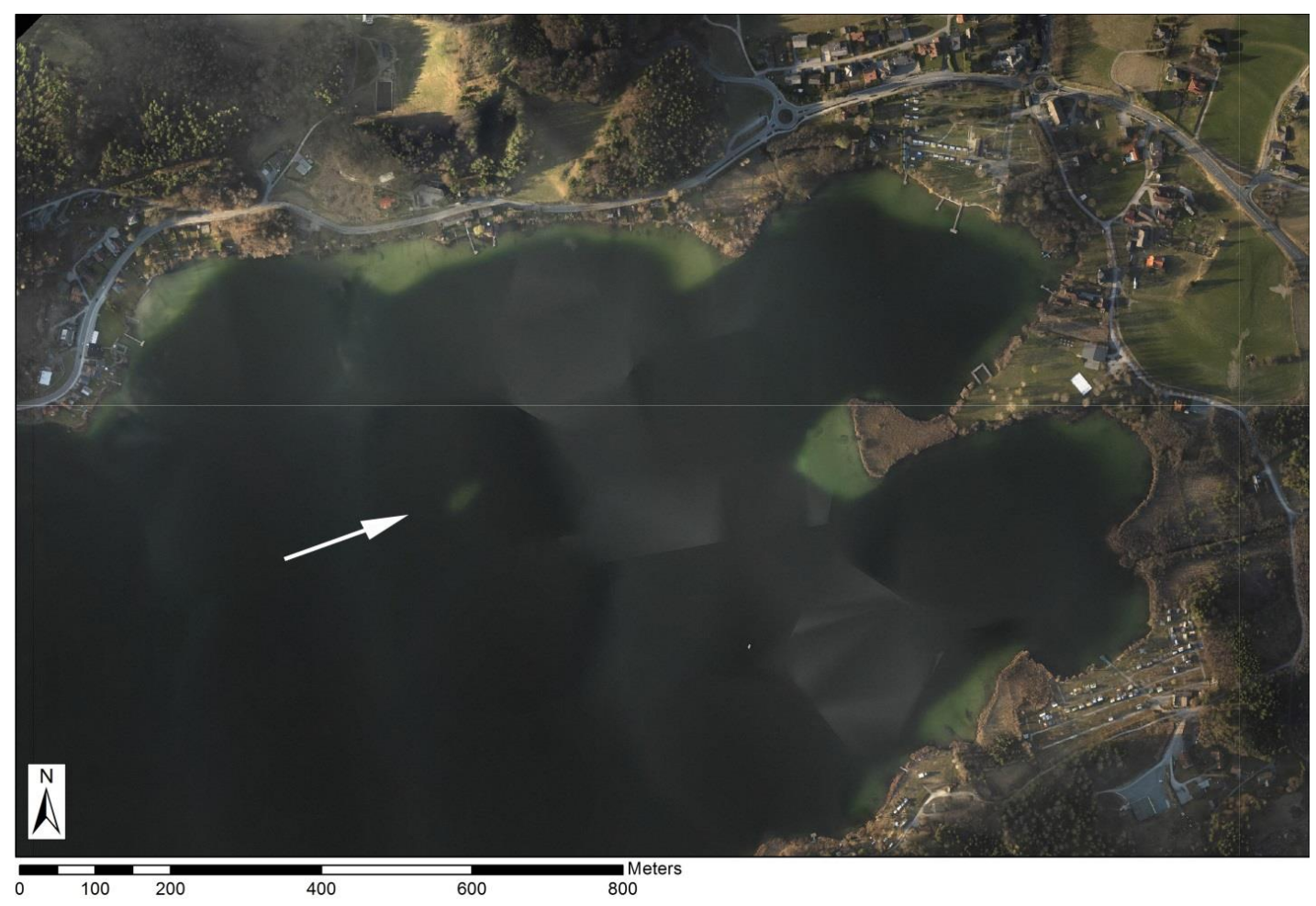

Figure 4. Case study area of Lake Keutschach. Simultaneously acquired orthophoto mosaic. The arrow hints at the oval shaped shallowness, where the late Neolithic lake dwelling is located. 

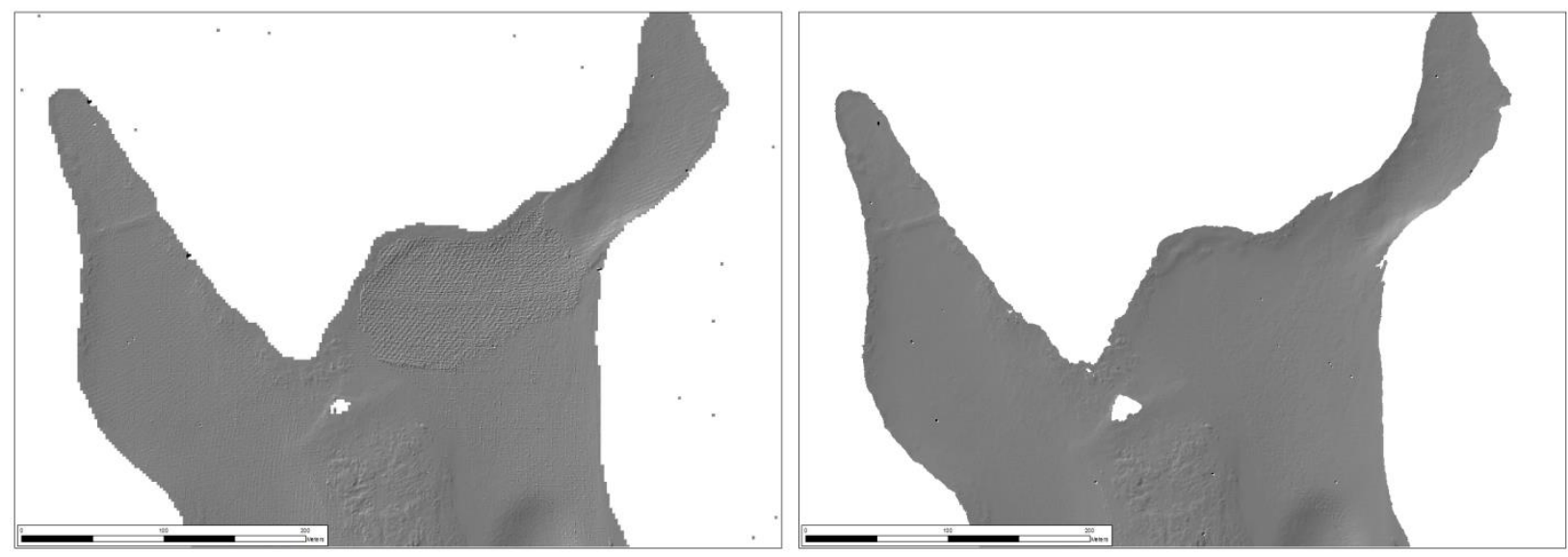

Figure 5. Hillshade of underwater DTM derived from the unfiltered last echo point cloud without (left image) and with (right image) strip adjustment.

\subsection{Data Acquisition and Processing}

The data for both case studies were acquired at the end of March 2012 using an airborne RIEGL VQ-820-G topobathymetric laser scanner operated by Airborne Technologies $\mathrm{GmbH}$. Lake Keutschach was covered on the $28^{\text {th }}$ of March around 18:30, while Kolone was documented on the $29^{\text {th }}$ of March around 12:30 local time, both at calm water conditions. The flying height was approximately $450 \mathrm{~m}$ above ground level, which resulted in footprints of $0.45 \mathrm{~m}$ diameter on the water surface. The effective measurement rate was approximately $200 \mathrm{kHz}$. To guarantee eye-safety, the low energy mode, which is a special instrument setting provided by RIEGL, was used. The scan angle was set to the full field of view of the instrument ( 60 degrees).

Due to the difficulties of deriving DTMs from ALB (see above), the process of deriving underwater surfaces from ALB data is slightly complicated (Mandlburger et al., 2014). It comprises:

$>$ Echo detection and generation of a 3D point cloud from the scanner, GNSS and IMU data.

$>$ Strip adjustment and quality control (Figure 5).

$>$ Calculating a water surface model for subsequent refraction correction.

$>$ Range and refraction correction of water echoes based on the water surface model.

$>$ Classification of surface and off-surface points (both within and outside the water body).

$>$ DTM interpolation.

$>$ Calculating visualizations (typically hillshade, slope, local relief model, openness).

$>$ GIS-based archaeological interpretation.

Echo detection was realized using the scanner's online waveform processing capability (see (Pfennigbauer and Ullrich, 2009). The data was processed by Airborne Technologies GmbH using the software RiPROCESS. This resulted in a total point cloud (including all echoes) with a density of at least 10 points per square meter.

To calculate the range and execute a proper refraction correction, an accurate model of the contemporary conditions and shape of the water surface is essential since the speed of electromagnetic radiation differs for atmosphere and water. While the operated system gave already good results, remaining systematic errors between the strips could be minimized using least square adjustment of the individual scanning stripes (Ressl et al., 2009) utilizing the software package OPALS (Mandlburger et al., 2009; Pfeifer et al., 2014; see also Figure 5).

Filtering off-surface points from the resulting point cloud was done using robust interpolation with an eccentric and asymmetrical weight function (see Doneus et al., 2008, p. 887). From the remaining point cloud, a DTM with a spatial resolution of $0.5 \mathrm{~m}$ was derived, which was finally imported into a GIS environment for further visualisation (Hesse, 2010; Bennett et al., 2012; Doneus, 2013; Kokalj et al., 2013) and interpretation.

\section{RESULTS}

In Kolone the digital model of the underwater topography could be derived at depths of up to 11 meters. The DTM and its visualisations allow recognizing several structures that could be verified during underwater surveys (Figures 6 and 7). The integrated interpretation and various architectural remains imply two fish ponds: while the western part of the bay is dominated by the large and deep fish pond (A), a structure with square layout and architectural elements found nearby represents a smaller one $(\mathrm{E})$. This structure $(15 \times 15 \mathrm{~m})$ does not represent a wall but a tesselation or a paved area. It stretches by the edge of the structure and is around 3 meters wide. Diving surveys revealed a few stone slabs within both fish ponds. One stone slab $(2 \times 0,9 \mathrm{~m})$ with two incised rectangular fields was found inside the fish pond (E). Another identical stone slab was found on the northern edge of the fish pond (A), between the pier (B) and fish pond (A). A third stone slab was found in the fish pond structure (A). It comprises of a round hole on one half and an opening or some kind of a lid on the edge. The second half of the slab contains a stone grid. The function of the slabs is yet unknown, but it may be assumed they were a segment of stone elements used to construct the fish pond, probably allowing water to circulate to and fro the fish ponds. 


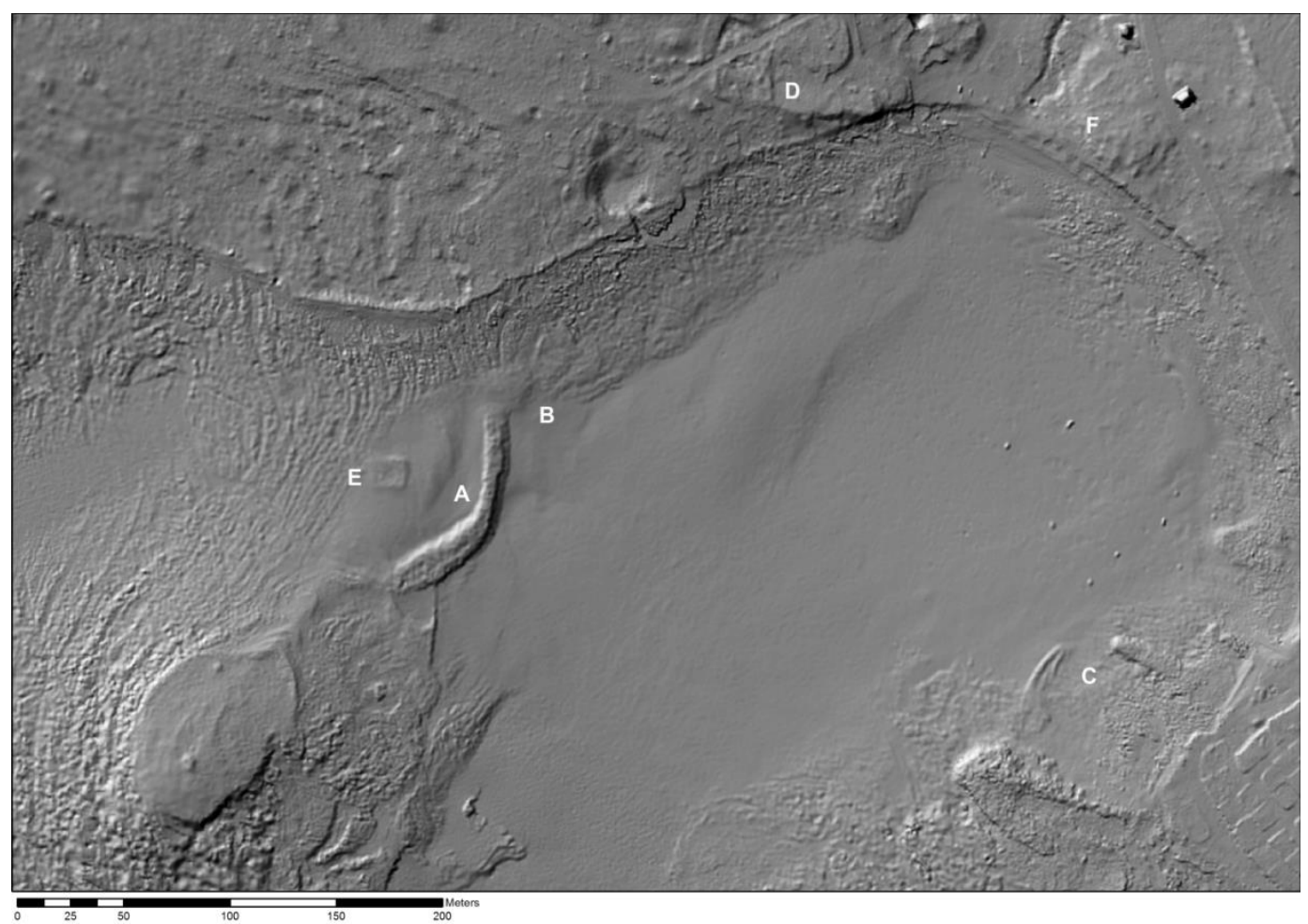

Figure 6. Shaded digital surface model generated from the filtered and strip-adjusted ALB-point cloud over the Roman harbour site of Kolone, Croatia.

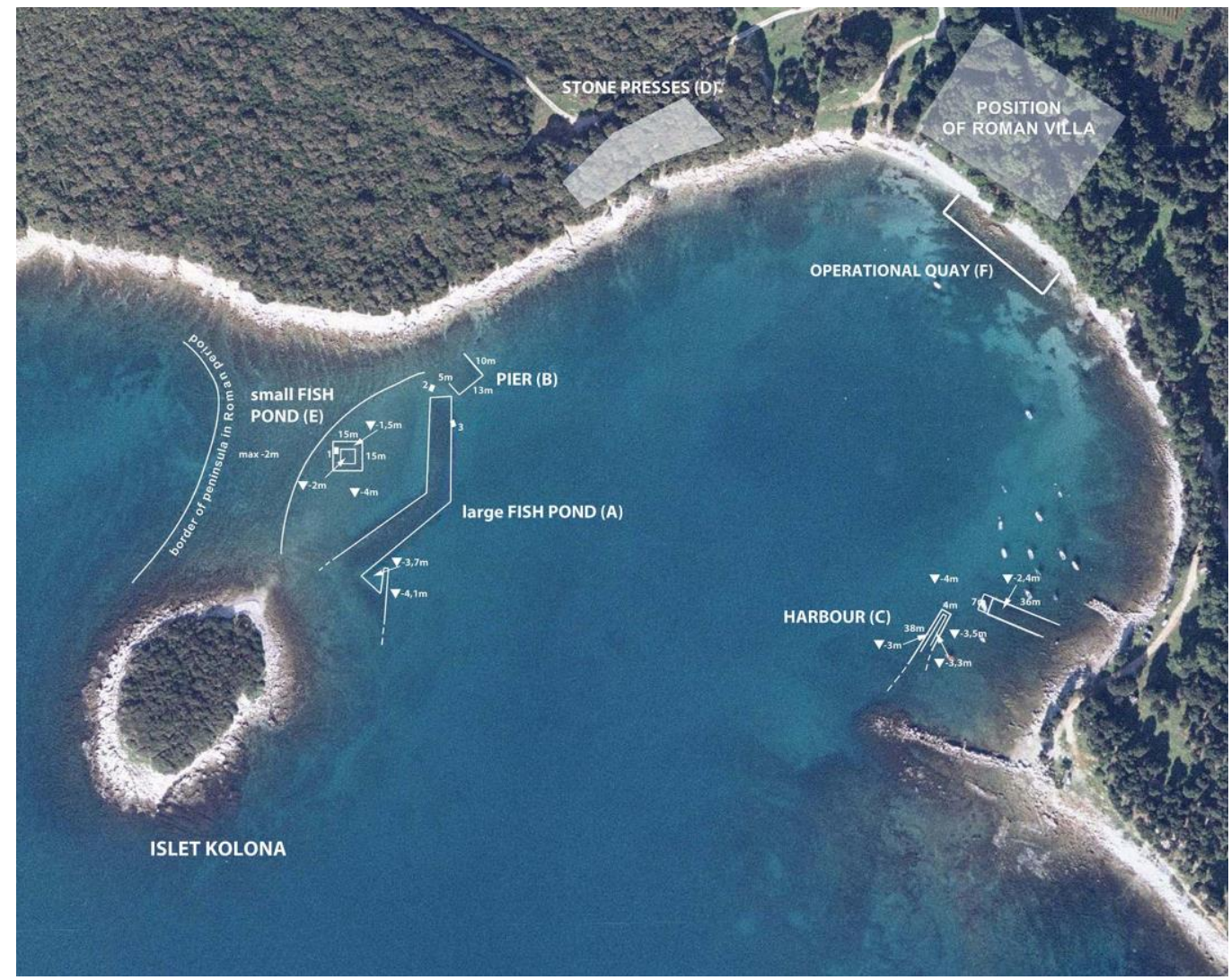

Figure 7. Interpretation drawing based on ALB derived visualizations and underwater survey @ Igor Miholjek. 

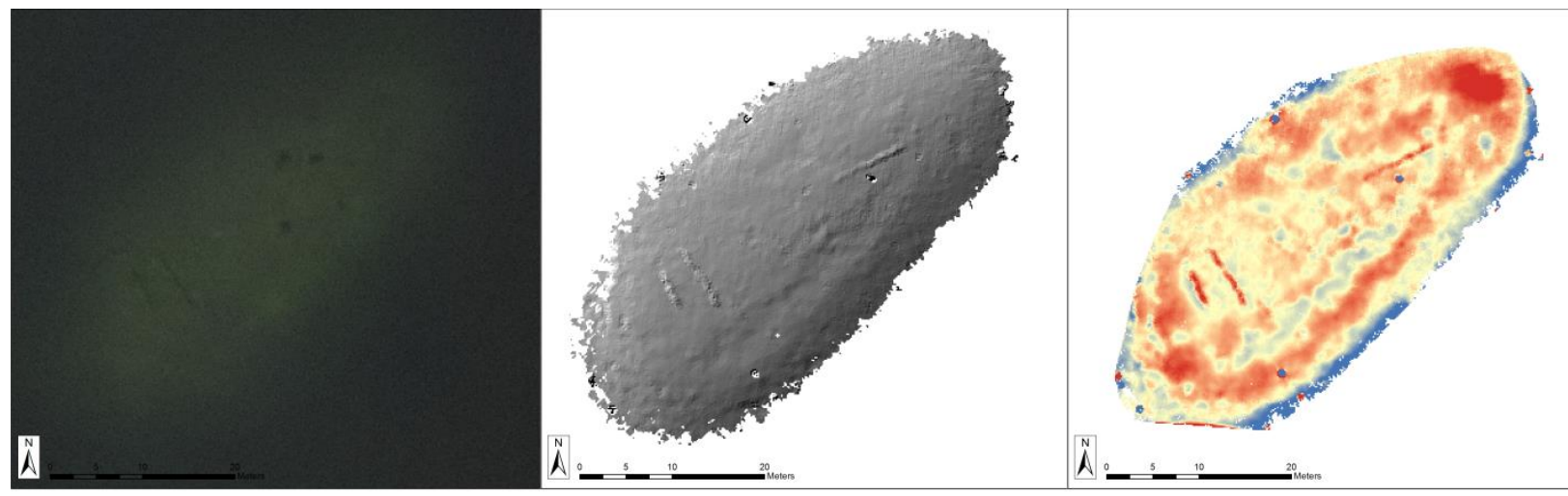

Figure 8. Keutschach, Austria. Traces of a late Neolithic lake dwelling. Left: simultaneously acquired orthophoto; middle: hillshade of ALB derived DTM (light source in upper left corner); right: local relief model of the ALB derived DTM (kernel size $=12.5 \mathrm{~m})$.

The "breakwater" is built from smaller pieces of stone without the use of a binding agent (mortar) and is around $150 \mathrm{~m}$ long and 10 $\mathrm{m}$ wide. Pier remains (B) were discovered north of the fish pond. They consist of a line of blocks stretching $13 \mathrm{~m}$ long and 10 meters wide.

Remains of a Roman harbour (C) are located in the eastern part of the bay, large enough to service the needs of a Roman villa. The harbour is enclosed from the south, west and north by a breakwater constructed of smaller stones built without binding agent. Large amounts of archaeological material are still preserved inside the breakwater. The Roman villa is situated in the eastern part of the bay along with its operational quay (F). Stone presses remains (D) are maybe an indication of oil or wine production or were used in the process of dying fabrics (fullonicae).

The turbid Lake Keutschach exhibits a much lower Secchi depth. This can be seen in the aerial photograph, which was acquired simultaneously with the ALB data acquisition (Figure 8). The underwater surface is only visible within a narrow band along the lakeshore and a small, $30 \mathrm{~m}$ by $60 \mathrm{~m}$ wide oval shallowness (water depth roughly $1.6 \mathrm{~m}$ ) within the lake, which is the location of the late Neolithic lake dwelling. Again, the penetration depth of the ALB system is in the range of one Secchi depth (roughly $1.6 \mathrm{~m}$ ) and the documented lake floor coincides with the visible area from the aerial photograph. The spatial resolution, however, is high and allows differentiating individual wooden logs lying on the lake floor.

\section{DISCUSSION}

ALB for documentation of submerged archaeological remains has been discussed in more detail already before (Doneus et al., 2013, 2146ff.). Most importantly the results clearly demonstrate that ALB can document both land and underwater surfaces with a single device and at a single data acquisition flight. This allows to systematically document and survey the topography of extremely shallow-water zones over large areas in high spatial resolution.

Only the first $25 \mathrm{~cm}$ of the water column can be theoretically problematic if an individual laser pulse is reflected both from the water surface and the sea floor (Mandlburger et al., 2011, p. $3422)$.
It has to be stressed that a major advantage of ALB compared to other hydrographic methods (mainly different versions of sonar sound navigation and ranging) is the short acquisition time needed. ALB can thus be used over large areas to rapidly assess potential archaeological traces and topographical features. Any further detailed information can subsequently be gathered using sonar in smaller predefined areas, an integration already proposed by Danson (2006).

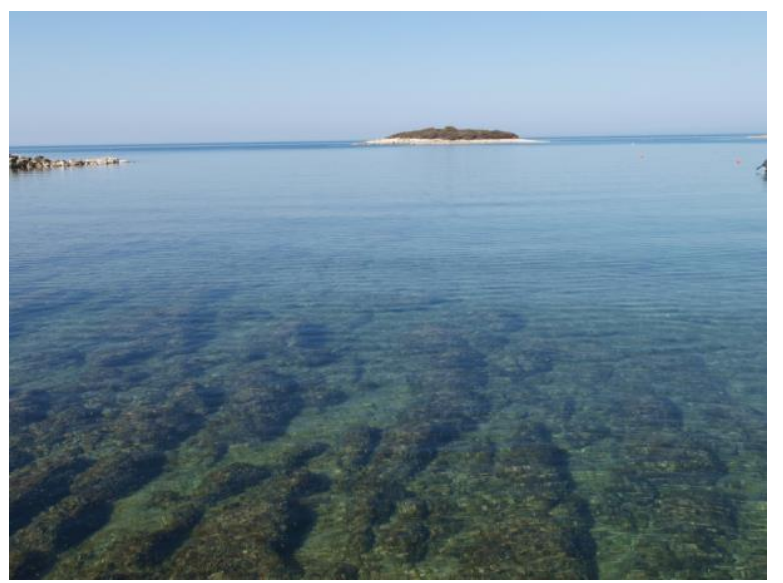

Figure 9. Kolone, Croatia. The photograph was taken on March 29 around 12.30 during the ALB data acquisition and documents the smooth water surface and this calm and almost windless day

(Photo: Davor Milošević).

However, only archaeological sites and structures still surviving in (micro-) relief can be visualised and identified. This also holds for sonar and ALS, and may result in a biased archaeological record. Also, a high quality DTM is necessary in order to be able to interpret individual archaeological structures. Therefore, only the latest generation of ALB systems from Leica, Optech, or RIEGL can be successfully applied for this kind of research. This means, that currently, there is a trade-off between detail and water depth, where $0.5 \mathrm{~m}$ resolution can be achieved only up to $1.5 \mathrm{Secchi}$ depths.

In Kolone, the penetration depth of up to $11 \mathrm{~m}$ was achieved on a calm day and over clear water with a relatively smooth water 
surface, as can be seen in (Figures 3, 8 and 9). These are ideal conditions. The results can thus not be applied to other parts of the world, as could be showed in the second case study of Lake Keutschach.

We anticipate this technique also as a major break-through in scientific fields that are in need of detailed topographic maps of intertidal zones and shallow-water bodies. Furthermore, multitemporal ALB missions could reveal environmental change regarding underwater sedimentation and erosion rates (Mandlburger et al., 2014), as well as changes in underwater vegetation.

\section{CONCLUSION}

Our results demonstrate the potential of airborne laser bathymetry to map submerged archaeological structures over large areas in high detail, for the first time providing the possibility for systematic, large-scale archaeological investigation of this environment. Utilizing green lasers, it has become possible to shift the measurement border from the water-land boundary into the water. This allows including shallow-water zones, which can otherwise hardly be mapped in detail, into topographic documentation.

\section{ACKNOWLEDGEMENTS}

The flight was funded by RGZM Mainz in preparation of the project "Harbours and landing places on the Balkan coasts of Byzantine empire (4.-12. Century). Technology and monuments, economic and communication."

Gottfried Mandlburger was supported by the Austrian Research Promotion Agency (FFG) COMET-K project "Airborne Alphine Hydro Mapping - From Research to Practice (AAHM-R2P)"

The Ludwig Boltzmann Institute for Archaeological Prospection and Virtual Archaeology (archpro.lbg.ac.at) is based on an international cooperation of the Ludwig Boltzmann Gesellschaft (A), the University of Vienna (A), the Vienna University of Technology (A), the Austrian Central Institute for Meteorology and Geodynamic (A), the office of the provincial government of Lower Austria (A), 7Reasons (A), RGZM-Roman - Germanic Central Museum Mainz (D), RÄ̈-Swedish National Heritage Board (S), IBM VISTA-University of Birmingham (GB), NIKUNorwegian Institute for Cultural Heritage Research (N), and Vestfold County Council (N).

\section{REFERENCES}

AHAB 2014. HawkEye III data sheet. url: http://www.airbornehydro.com/sites/default/files/Leica\%20AHAB \%20HawkEye\%20III.pdf, last accessed: 17.02.2015.

Bennett, R., Welham, K., Hill, R.A., Ford, A., 2012. A Comparison of Visualization Techniques for Models Created from Airborne Laser Scanned Data. Archaeological Prospection 19, 4148 .

Briese, C., Pfennigbauer, M., Ullrich, A., Doneus, M., 2014. Radiometric Information from Airborne Laser Scanning for
Archaeological Prospection. International Journal of Heritage in the Digital Era 3 (1), 159-178.

Bukata, R.P., Jerome, J.H., Kondratyev, K.Y., Pozdnyakov, D.V., 1995. Optical properties and remote sensing of inland and coastal waters. CRC Press, Boca Raton.

Carbonneau, P.E., Lane, S.N., Bergeron, N., 2006. Feature based image processing methods applied to bathymetric measurements from airborne remote sensing in fluvial environments. Earth Surf. Process. Landforms 31 (11), 1413-1423.

Cichocki, O., Dworsky, C., 2006. Unterwasserarchäologie in Kärntner Seen. Archäologie Österreichs (Festschrift E. Ruttkay). 17/2 (2006): 90 - 95, 9 Abb., Wien.

Cunningham, A., Lillycrop, W., Guenther, G.C., Brooks, M.W., 1998. Shallow water laser bathymetry: accomplishments and applications. Oceanology International 3, 277-288.

Danson, E., 2006. Understanding LiDAR Bathymetry for Shallow Waters and Coastal Mapping, in: Shaping the Change. Proceedings of the XXIII FIG Congress, Munich, Germany. October 8-13, 2006.

Doneus, M., 2013. Openness as Visualization Technique for Interpretative Mapping of Airborne Lidar Derived Digital Terrain Models. Remote Sensing of Environment (5), 6427-6442.

Doneus, M., Briese, C., Fera, M., Janner, M., 2008. Archaeological prospection of forested areas using full-waveform airborne laser scanning. Journal of Archaeological Science 35, 882-893.

Doneus, M., Briese, C., 2011. Airborne Laser Scanning in Forested Areas - Potential and Limitations of an Archaeological Prospection Technique. In: Cowley, D. (Ed.), Remote Sensing for Archaeological Heritage Management. Proceedings of the 11th EAC Heritage Management Symposium, Reykjavik, Iceland, 2527 March 2010. Archaeolingua; EAC, Budapest, pp. 53-76.

Doneus, M., Doneus, N., Briese, C., Pregesbauer, M., Mandlburger, G., Verhoeven, G., 2013. Airborne Laser Bathymetry - detecting and recording submerged archaeological sites from the air. Journal of Archaeological Science 40, 21362151.

Guenther, G.C., Cunningham, A., Laroque, P., Reid, D., 2000. Meeting the accuracy challenge in airborne lidar bathymetry. In: Workshop on Lidar Remote Sensing of Land and Sea. Proceedings of the 20th EARSeL Symposium, Dresden/FRG, June $16-17,2000$, Dresden, pp. 1-27.

Hesse, R., 2010. LiDAR-derived Local Relief Models - a new tool for archaeological prospection. Archaeological Prospection 17 (2), $67-72$.

Jong, C.D. de, 2002. Hydrography, 1st ed. DUP Blue Print, Delft.

Kokalj, Ž., Zakšek, K., Oštir, K., 2013. Visualizations of lidar derived relief models. In: Opitz, R.S., Cowley, D. (Eds.), Interpreting archaeological topography. Airborne laser scanning, 3D data and ground observation. Oxbow Books, Oxford, pp. 100114. 
Lambeck, K., Anzidei, M., Antonioli, F., Benini, A., Esposito, A., 2004. Sea level in Roman time in the Central Mediterranean and implications for recent change. Earth and Planetary Science Letters 224, 563-575.

Mandlburger, G., Otepka, J., Karel, W., Wagner, W., Pfeifer, N., 2009. Orientation and Processing of Airborne Laser Scanning data (OPALS) - concept and first results of a comprehensive ALS software. In: Bretar, F., Pierrot-Deseilligny, M., Vosselman, G. (Eds.), ISPRS Workshop Laserscanning '09. Paris, France, September $1-2$, 2009. Société Française de Photogrammétrie et de Télédétection.

Mandlburger, G., Pfennigbauer, M., Steinbacher, F., Pfeifer, N., 2011. Airborne Hydrographic LiDAR Mapping - Potential of a new technique for capturing shallow water bodies. In: Chan, F., Marinova, D., Anderssen, R. (Eds.), MODSIM2011, 19th International Congress on Modelling and Simulation. Modelling and Simulation Society of Australia and New Zealand, December 2011, Perth, pp. 2416-2422.

Mandlburger, G., Hauer, C., Wieser, M., 2014. Monotoring of instream habitats with focus on morphological dynamics based on Airborne Laser Bathymetry, in: Proceedings of the International Workshop on Remote Sensing and GIS for Monitoring of Habitat Quality. Vienna, 24-25 September 2014. International Workshop on Remote Sensing and GIS for Monitoring of Habitat Quality, Wien; 2014-09-24 -- 2014-09-25, Department of Geodesy and Geoinformation, Vienna University of Technology, Vienna, pp. $30-34$.

McNair, G., 2010. Coastal Zone Mapping with Airborne LiDAR Bathymetry. Master Thesis, Ås.

Optech 2014. Optech Titan data sheet. url: http://www.optech.com/index.php/product/titan/, last accessed 17.02.2015.

Pfeifer, N., Mandlburger, G., Otepka, J., Karel, W., 2014. OPALS - A framework for Airborne Laser Scanning data analysis. Computers, Environment and Urban Systems 45, 125-136.

Pfennigbauer, M., Ullrich, A., 2009. The new RIEGL V-Line Laser Scanner's higher Data Quality using new Measurement Principles. In: Optical 3D Measurement Techniques, Vienna.

Pope, R.M., Fry, E.S., 1997. Absorption spectrum (380-700 nm) of pure water. II. Integrating cavity measurements. Appl. Opt. 36 (33), 8710-8723.

Prahov, N., Angelova, H., Kotsev, A., Popov, A., Dimitrov, S., 2011. Predictive modeling in archaeology: World practice and Bulgarian perspectives. Bulgarian e-Journal of Archaeology 1, 71-121.

Preisendorfer, R.W. Secchi disk science: Visual optics of natural waters. Limnol. Oceanogr. 1986, 31, 909-926.

Ressl, C., Mandlburger, G., Pfeifer, N., 2009. Investigating Adjustment Of Airborne Laser Scanning Strips Without Usage Of GNSS/IMU Trajectory Data. In: Bretar, F., Pierrot-Deseiligny, M., Vosselman, G. (Eds.), Laserscanning09. Paris, France, September 1-2, 2009, Paris, pp. 195-200.
Riegl, 2012. VQ-820-G data sheet. url: http://http://www.riegl.com/uploads/tx_pxpriegldownloads/DataS heet_VQ-820-G_2014-09-19.pdf, last accessed: 17.02.2015.

Riegl, 2014. VQ-880-G data sheet. url: http://www.riegl.com/uploads/tx_pxpriegldownloads/VQ-880G_at_a_glance_2014-10-01.pdf, last accessed 17.02.2015.

Samonig, B., 2003. Studien zur Pfahlbauforschung in Österreich. Materialien II. Die Pfahlbaustation des Keutschacher Sees. Mitteilungen der Prähistorischen Kommission Österr. Akad. Wiss. 51, 263 - 282. Wien.

Tian-Yuan Shih, P., Chen, Y.-H., Chen, J.-C., 2014. Historic Shipwreck Study in Dongsha Atoll with Bathymetric LiDAR. Archaeological Prospection 21 (2), 139-146.

Wang, C.-K., Philpot, W.D., 2007. Using airborne bathymetric lidar to detect bottom type variation in shallow waters. Remote Sensing of Environment 106, 123-135. 